\title{
Ectopic bone formation by aggregated mesenchymal stem cells from bone marrow and adipose tissue: $A$ comparative study
}

Citation for published version (APA):

Fennema, E. M., Tchang, L. A. H., Yuan, H., van Blitterswijk, C. A., Martin, I., Scherberich, A., \& de Boer, J. (2018). Ectopic bone formation by aggregated mesenchymal stem cells from bone marrow and adipose tissue: A comparative study. Journal of Tissue Engineering and Regenerative Medicine, 12(1), E150-

E158. https://doi.org/10.1002/term.2453

Document status and date:

Published: 01/01/2018

DOI:

10.1002/term.2453

Document Version:

Publisher's PDF, also known as Version of record

\section{Document license:}

Taverne

Please check the document version of this publication:

- A submitted manuscript is the version of the article upon submission and before peer-review. There can be important differences between the submitted version and the official published version of record.

People interested in the research are advised to contact the author for the final version of the publication, or visit the DOI to the publisher's website.

- The final author version and the galley proof are versions of the publication after peer review.

- The final published version features the final layout of the paper including the volume, issue and page numbers.

Link to publication

\footnotetext{
General rights rights.

- You may freely distribute the URL identifying the publication in the public portal. please follow below link for the End User Agreement:

www.umlib.nl/taverne-license

Take down policy

If you believe that this document breaches copyright please contact us at:

repository@maastrichtuniversity.nl

providing details and we will investigate your claim.
}

Copyright and moral rights for the publications made accessible in the public portal are retained by the authors and/or other copyright owners and it is a condition of accessing publications that users recognise and abide by the legal requirements associated with these

- Users may download and print one copy of any publication from the public portal for the purpose of private study or research.

- You may not further distribute the material or use it for any profit-making activity or commercial gain

If the publication is distributed under the terms of Article $25 \mathrm{fa}$ of the Dutch Copyright Act, indicated by the "Taverne" license above, 


\title{
Ectopic bone formation by aggregated mesenchymal stem cells from bone marrow and adipose tissue: A comparative study
}

\author{
Eelco M. Fennema ${ }^{1}$ (D) । Laurent A.H. Tchang ${ }^{2}$ । Huipin Yuan ${ }^{3,4}$ । \\ Clemens A. van Blitterswijk ${ }^{1,3}$ | Ivan Martin ${ }^{2}$ | Arnaud Scherberich ${ }^{2}$ | Jan de Boer ${ }^{1,3}$
}

\author{
${ }^{1}$ Department of Tissue Regeneration, MIRA \\ Institute for Biomedical Technology and \\ Technical Medicine, University of Twente, \\ Enschede, the Netherlands \\ ${ }^{2}$ Department of Biomedicine, University \\ Hospital Basel, University of Basel, Basel, \\ Switzerland \\ ${ }^{3}$ MERLN Institute for Technology-inspired \\ Regenerative Medicine, Maastricht University, \\ Maastricht, the Netherlands \\ ${ }^{4}$ Xpand Biotechnology B.V., Bilthoven, the \\ Netherlands \\ Correspondence \\ Jan de Boer, MERLN Institute for Technology- \\ inspired Regenerative Medicine, Maastricht \\ University, Maastricht, the Netherlands \\ Email: jan.deboer@maastrichtuniversity.nl
}

Funding information

Dutch Province of Limburg; Pieken in de Delta Oost-Nederland, Grant/Award Number: PID091014; Swiss National Science Foundation, Grant/Award Number: 310030-138519

\section{1 | INTRODUCTION}

Bridging critical sized bone defects is one of the main current challenges in orthopaedic and trauma surgery. These defects can result from resection of bone tumours, trauma or infection and affect mainly younger patients. The current gold standard for bridging these defects is autologous grafting of bone from the iliac crest or proximal tibia. The complications, donor site infection and pain, of these procedures are well known and frequently mentioned as arguments for alternative solutions. One is the use of bone graft substitutes with mesenchymal stromal or stem cells (MSCs) derived from bone marrow combined with biomaterials, and sometimes growth factors, to be delivered into

\begin{abstract}
Tissue engineered constructs (TECS) based on spheroids of bone marrow mesenchymal stromal cells (BM-MSCs) combined with calcium phosphate microparticles and enveloped in a plateletrich plasma hydrogel showed that aggregation of MSCs improves their ectopic bone formation potential. The stromal vascular fraction (SVF) and adipose-derived MSCs (ASCs) have been recognized as an interesting MSC source for bone tissue engineering, but their ectopic bone formation is limited. We investigated whether aggregation of ASCs could similarly improve ectopic bone formation by ASCs and SVF cells. The formation of aggregates with BM-MSCs, ASCs and SVF cells was carried out and gene expression was analysed for osteogenic, chondrogenic and vasculogenic genes in vitro. Ectopic bone formation was evaluated after implantation of TECs in immunodeficient mice with six conditions: TECs with ASCs, TECs with BM-MSC, TECs with SVF cells (with and without rhBMP2), no cells and no cells with rhBMP2. BM-MSCs showed consistent compact spheroid formation, ASCs to a lesser extent and SVF showed poor spheroid formation. Aggregation of ASCs induced a significant upregulation of the expression of osteogenic markers like alkaline phosphatase and collagen type I, as compared with un-aggregated ASCs. In vivo, ASC and SVF cells both generated ectopic bone in the absence of added morphogenetic proteins. The highest incidence of bone formation was seen with BM-MSCs (7/9) followed by SVF + rhBMP2 (4/9) and no cells + rhBMP2 (2/9). Aggregation can improve ectopic bone tissue formation by adipose-derived cells, but is less efficient than rhBMP2. A combination of both factors should now be tested to investigate an additive effect.
\end{abstract}

\section{KEYWORDS}

adipose tissue, BMP2, bone marrow, bone regeneration, mesenchymal stromal cells, spheroids 
are commonly used in skeletal tissue engineering in vitro and in vivo (Gamie et al., 2012).

We have extensively used ceramic scaffolds in combination with BM-MSCs in two-dimensional (Meijer, de Bruijn, Koole, \& van Blitterswijk, 2008; Siddappa et al., 2008). More recently, we developed a three-dimensional culture system to generate tissue engineered constructs (TECS) based on spheroids of MSCs with an average diameter of $140 \mu \mathrm{m}$, mixed with porous calcium phosphate ceramic particles of 53-63 $\mu \mathrm{m}$ in diameter and enveloped by a platelet-rich plasma hydrogel. This system demonstrated more bone formation than the standard two-dimensional approach (Chatterjea et al., 2013; Rivron et al., 2012,). In general, three-dimensional culturing techniques confer a higher degree of clinical relevance to preclinical studies than twodimensional. For example, primary rat hepatocytes showed positive signalling for Connexin 32 again after aggregation (Bierwolf et al., 2011) and Pannexin 1, a gap junction protein, plays a pivotal role in aggregate assembly and, hence, in intercellular biomechanical interactions that drive the progression of cancer (Bao, Lai, Naus, \& Morgan, 2012).

ASCs have also been used in three-dimensional culture systems aiming at skeletal tissue engineering. However, bone formation by ASCs was only seen after preculturing (Güven et al., 2011) and/or the addition of rhBMP2 (Shen et al., 2013). To increase the clinical applicability, we aim to shorten in vitro culture times as much as possible. Furthermore, the incorporation of growth factors brings about extensive clinical testing before it can be applied in patients, and has only a few indications (e.g. spinal fusion).

Therefore, the aim of this study was to analyse the use of aggregated SVF, ASCs or BM-MSC for bone tissue engineering in the form of TECs without the addition of morphogenetic growth factors. For each of these cell sources, we compared the differences in differentiation in vitro and bone formation in vivo.

\section{2 | MATERIALS AND METHODS}

\section{1 | Cell culture}

Bone marrow aspirates $(5-20 \mathrm{ml})$ were obtained from healthy donors during hip replacement surgery with written informed consent and MSCs were isolated as described previously (Siddappa, Licht, van Blitterswijk, \& de Boer, 2007). Basic medium was made up of a-minimal essential medium (a-MEM; Life Technologies), 10\% fetal bovine serum (Cambrex), $0.2 \mathrm{mM}$ ascorbic acid (Asap; Life Technologies), $2 \mathrm{mM}$ L-glutamine (Life Technologies), $100 \mathrm{U} / \mathrm{ml}$ penicillin (Life Technologies) and $10 \mathrm{mg} / \mathrm{ml}$ streptomycin (Life Technologies). Proliferation medium consisted of basic medium supplemented with $1 \mathrm{ng} / \mathrm{ml}$ basic fibroblast growth factor (Instruchemie, the Netherlands). Induction medium (for osteogenic differentiation studies and prior to in vivo implantation) was composed of D-MEM (Life Technologies) supplemented with $10^{-7} \mathrm{M}$ dexamethasone (Sigma-Aldrich, USA), $50 \mathrm{mg} / \mathrm{ml}$ ascorbic acid (Life Technologies), $40 \mathrm{mg} / \mathrm{ml}$ proline (Sigma-Aldrich), $100 \mathrm{mg} / \mathrm{ml}$ sodium pyruvate (Life Technologies), $50 \mathrm{mg} / \mathrm{ml}$ ITS Premix (Becton-Dickinson, USA). Mineralization medium consisted of basic medium with $10^{-8} \mathrm{M}$ dexamethasone (Sigma-Aldrich) and $0.01 \mathrm{M} \beta$ - glycerol phosphate (Sigma-Aldrich). Adipogenic medium was composed of D-MEM (Life Technologies), $100 \mathrm{U} / \mathrm{ml}$ penicillin $+100 \mathrm{mg} / \mathrm{ml}$ streptomycin (Life Technologies), 10\% fetal bovine serum (Cambrex), $0.2 \mathrm{mM}$ indomethacin (Sigma-Aldrich), $0.5 \mathrm{mM}$ IBMX (Sigma-Aldrich), $10^{-6} \mathrm{M}$ dexamethasone (Sigma-Aldrich) and $10 \mathrm{mg} / \mathrm{ml}$ insulin (human, SigmaAldrich). Cells were grown at $37^{\circ} \mathrm{C}$ in a humid atmosphere with $5 \%$ $\mathrm{CO}_{2}$. Medium was refreshed every 3-4 days. Cells were grown to near confluence in proliferation medium before their use in experiments.

Lipoaspirates, $10-100 \mathrm{ml}$, were obtained from donors during routine lipoaspirations of the inner and/or outer thighs after informed consent from the patient and following protocol approval by the local ethical committee. SVF cells were obtained after digestion of lipoaspirates in $0.075 \%$ collagenase type 2 (Worthington Biochem USA) for $45 \mathrm{~min}$ at $37^{\circ} \mathrm{C}$ on an orbital shaker (Scherberich, Galli, Jaquiery, Farhadi, \& Martin, 2007). SVF cells were allowed to adhere to tissue culture plastic in proliferation medium and trypsinized when reaching near confluence. These cells were ASCs. ASCs were derived from the same donors as the SVF cells.

Spheroids were created using previously described methods (Chatterjea et al., 2013). In short, 1.5 million cells were seeded in microwells (400 $\mu \mathrm{m}$ diameter, $200 \mu \mathrm{m}$ depth) on a patterned agarose chip (surface area $3.8 \mathrm{~cm}^{2}$ ). After $24 \mathrm{~h}$, spheroids were formed in most cases. We fabricated the TECs as described previously (Chatterjea et al., 2013). Briefly, 1.5 million cells in spheroids were combined with calcium phosphate ceramic scaffolds and a platelet-rich plasma gel and these were cultured in basic or induction medium for 1 day prior to implantation or 7 days in case of in vitro analysis. To compare TECs prior to implantation, SVF-, ASC- and BM-MSC-based TECs were analysed by histology. Two BM-MSC donors were used and one SVF and one ASC donor was used. Both BM-MSCs and ASCs were P1-2 cells.

\section{2 | Differentiation experiments}

The adipogenic differentiation protocol was as follows: human MSCs were seeded at 10000 cells $/ \mathrm{cm}^{2}$ and grown in adipogenic medium for 21 days. Medium was refreshed every 3-4 days and lipid formation was visualized after 21 days by Oil Red $O$ staining. In the mineralization protocol, human MSCs were seeded at $5000 / \mathrm{cm}^{2}$ and grown in mineralization medium in T25 culture flasks for 21-28 days until robust mineralization was observed in the positive control. Mineralization was visualized with Alizarin Red staining. Cells grown in basic medium plus $0.01 \mathrm{M} \beta$-glycerol phosphate (Sigma) were used as the negative control. SVFs could not be subjected to our two-dimensional adipogenic and mineralization assays as they could no longer be considered as SVFs but as ASCs.

\section{3 | Gene expression analysis}

TECs were rinsed with phosphate-buffered saline (PBS), crushed manually and lysed using Trizol (Invitrogen). After the addition of chloroform and phase separation by centrifugation, the aqueous phase was aspirated and mixed with an equal volume of $75 \%$ ethanol. This RNA containing mixture was processed for purification using an RNA isolation kit (Machery-Nagel Germany) according to the manufacturer's protocol. The RNA concentration was analysed by spectrophotometry using 
TABLE 1 Summary of bone formation in vivo. All the conditions are listed in the first column. When bone formation was observed this was counted relative to the total number of mice. Bone marrow mesenchymal stromal cells (BM-MSCs) showed the highest bone incidence, followed by stromal vascular fraction (SVF) + rhBMP2 and no cells + rhBMP2. When using other cell sources, bone formation can only be achieved reliably by the addition of rhBMP2

\begin{tabular}{lcc} 
& Bone & No bone \\
\hline BM-MSC & $7 / 9$ & $2 / 9$ \\
No cells & - & $9 / 9$ \\
No cells + rhBMP2 & $2 / 9$ & $7 / 9$ \\
SVF & $1 / 9$ & $8 / 9$ \\
SVF + rhBMP2 & $4 / 9$ & $5 / 9$ \\
ASC & $1 / 9$ & $8 / 9$ \\
\hline
\end{tabular}

ASC, adipose-derived mesenchymal stromal cells.

the Nanodrop 1000 (Isogen Life Science The Netherlands). cDNA was synthesized using iScript (Bio-rad USA). Quantitative polymerase chain reaction (qPCR) results were obtained with a double-stranded DNAbinding dye, SYBR Green (Invitrogen). Primers were acquired from Sigma and sequences are shown in Table 1. Real-time qPCR was performed and gene expression was normalized to either glyceraldehyde-3-phosphate dehydrogenase or $\beta 2$-microglobulin. Relative gene expressions were calculated using the $\Delta \Delta \mathrm{Ct}$ method.

\subsection{Animal experiments}

To assess the bone-forming capacity of TECs we analysed ectopic bone formation in immunodeficient mice. After an acclimatization period of at least 7 days, mice were used for further studies. To alleviate peri-operative pain, mice were administered Temgesic s.c. (Schering-Plough BV USA). The surgeries were carried out under general anaesthesia. Induction of anaesthesia consisted of $4 \%$ isoflurane, followed by $2-2.5 \%$ isoflurane to maintain general anaesthesia. Four equally spaced dorsal incision sites were disinfected with $70 \%$ ethanol. A pocket was created by making a small skin incision $(3 \mathrm{~mm})$, followed by spreading of the subcutaneous tissue with blunt scissors. One TEC per pocket was implanted. The skin was closed with resorbing sutures or staples. For each animal study, 10 immunodeficient male mice (Hsdcpb: NMRI-nu, Harlan) were used. For the implantations, the cells for the ASC and SVF TECs originated from the same donors (donors $257,262,267)$. Only one BM-MSC donor was used (D240) as reference. All ASCs and BM-BMCs were P1 cells. Mice were fed ad libitum. Of 10 mice, one mouse died from an infection. After 6 weeks of implantation, mice were terminated with $\mathrm{CO}_{2}$. Samples were excised directly after termination and stored in fixative. All animal experiments were approved by the local animal welfare committee of either Utrecht or Basel and performed by licensed personnel according to Dutch or Swiss law.

\section{5 | Histological analysis}

Upon explantation, samples were fixed in $4 \%$ paraformaldehyde. The samples were dehydrated using either a graded series of ethanol, after decalcification in EDTA-PBS solution for 5 days with daily renewal of the solution (paraffin-embedded samples), or a histological microwave (Milestone Histoprocessor Italy) with methyl methacrylate (MMA)-embedded samples. MMA-embedded samples were cut to slides of $10-15 \mu \mathrm{m}$ thickness using a diamond saw rotatory microtome (Leica SP1600); $7 \mu \mathrm{m}$ sections were generated from paraffin-embedded samples. MMA-embedded samples were stained with methylene blue and basic fuchsin. Paraffin-embedded samples were stained with haematoxylin/eosin or Mason-trichrome. In qualitative bone assessment, bone incidence per condition was counted, as well as the maturity of the bone formed. Bone formation was assessed qualitatively.

\subsection{Bone quantification and qualification}

A minimum of three sections per sample were used for quantification, equally spread across the sample. Slides from MMA-embedded samples were scanned using a Pathscan Enabler IV (Meyer Instruments USA); the paraffin-embedded samples were scanned using a Hamamatsu Nanozoomer 2.0-RS (Hamamatsu Japan). After digitalization of the slides, the bone and scaffold area were quantified by pseudo-colouring of the respective tissue and counting pixels using Adobe Photoshop CS5.

\section{7 | Statistical analyses}

Statistical analyses were performed using IBM SPSS Statistics 22. Prior to analyses, data were checked for normality. In the case of positively skewed data, logarithmic transformation assured normality. When two groups were compared, Student's $t$-test for paired groups was used. When more groups were compared, ANOVA with Bonferroni's correction for multiple comparisons was used. A $p$ value $<0.05$ was considered significant.

\section{3 | RESULTS}

\section{1 | BM-MSCs and ASCs both differentiate into osteoblasts and adipocytes}

To determine multipotency of the BM-MSCs and ASCs used in the present study they were cultured with mineralization and adipogenic medium, respectively. Both BM-MSCs and ASCs mineralized well in mineralization medium, whereas no mineral was observed in the control condition. Similarly, comparable levels of adipogenic differentiation were observed with both cell sources (Figure 1). As mentioned, SVF could not be subjected to our two-dimensional differentiation assays, as they would become ASCs then.

\section{2 | Spheroid formation is cell source dependent}

We previously observed more bone formation when aggregated BMMSCs were used as the cell source compared with single cells. Therefore, we analysed the capacity of ASCs and SVF cells for spheroid formation. Cells were seeded in agarose moulds and after centrifugation cells were left for $24 \mathrm{~h}$ in basic medium. Spheroid formation was 

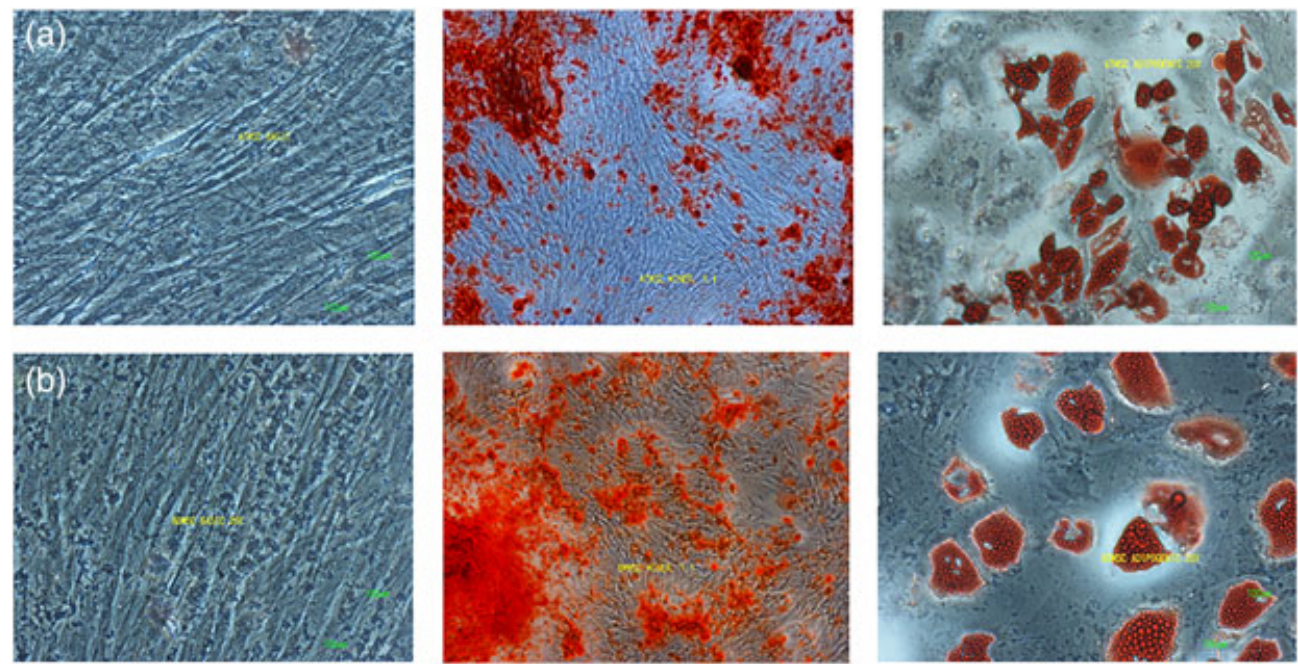

FIGURE 1 Adipose-derived (ASCs) and bone marrow mesenchymal stromal cells (BM-MSCs) show osteogenic and adipogenic differentiation. ASCs and BM-MSCs were differentiated into the osteogenic and adipogenic lineage. The upper row (a) shows ASCs, the bottom row BMBMSCs (b). From left to right are images of controls, mineralization and adipogenesis. No mineralization is present in the control (basic) conditions. Mineralization is visualized with Alizarin Red staining. The far right panels show intracellular fat droplets indicating that our cells successfully differentiated into adipocytes. The mineralization was more intense in BM-MSCs compared with ASCs. Adipogenic differentiation was the same as in ASCs. Scale bars indicate $100 \mu \mathrm{m}$

analysed by light microscopy. As observed previously, BM-MSC spheroid formation occurred within $24 \mathrm{~h}$ (Figure 2, fourth row). ASCs also formed spheroids, which appeared less compact, i.e. more translucent than the BM-MSC spheroids and not as 'rounded off' (Figure 2, third and fourth rows). SVF did not reliably form spheroids. Three SVF donors were used to illustrate the differences between donors. In donor 262, cells were seeded as single cells in the wells (Figure 2, first row) and, at best, there was only a poorly organized spheroid-like structure with SVF cells from donor 257 (Figure 2, second row). Spheroids were then implanted in vivo with Biphasic calcium phosphate (BCP) particles and an enveloping platelet-rich plasma gel after $24 \mathrm{~h}$ of exposure to induction medium. We analysed if cells were still in the form of spheroids upon implantation. Of the three cell sources, compact spheroids were only observed in BM-MSC-based TECS, whereas ASCs and SVF cells were not organized in spheroids in the samples but rather as single cells (data not shown). Hence, with this protocol, only BMMSCs reliably retained a spheroid configuration before implantation.

\section{3 | BM-MSC spheroids display a stronger osteogenic profile than ASCs and SVF cells}

To study the effect of aggregation on osteogenesis by ASCs and SVF cells, TECs were exposed to either induction medium or basic medium for 7 days. We thereafter determined the expression of osteogenic [BMP2, alkaline phosphatase (ALP) and collagen type I (Col I)], chondrogenic (Col II and Col X) and pro-angiogenic Vascular endothelial growth factor (VEGF) genes (Figure 3). With regards to the osteogenic profile, BMP2 was only increased 1.3-fold in BM-MSCs and decreased 0.7-fold in ASCs. Col I increased in both BM-MSCs and ASCs 1.4-fold and 2.9-fold, respectively, the latter being a significant increase. ALP expression also increased in both cell types upon exposure to induction medium compared with basic medium with 46-fold in BM-MSCs and 8-fold in ASCs, both significant increases. The expression of Col II similarly increased in both cell types, by 2.4-fold and 2.5-fold in BM-MSC and ASC, respectively, upon exposure to the induction medium. The expression of $\mathrm{Col} \mathrm{X}$ increased 4.7-fold in BM-MSCs but was undetectable in ASCs. VEGF expression decreased in both BM-MSCs and ASCs with 0.5- and 0.6-fold, respectively, both not significantly. The most obvious differences between BM-MSCs and ASCs were therefore in ALP and Col $\mathrm{X}$ expression patterns. This may indicate that ASCs are less committed to the osteogenic lineage compared with BM-MSCs. More generally, the response to osteogenic induction medium was highly similar in BMMSCs and ASCs.

\subsection{TECs made with BM-MSCs are superior in bone incidence and maturity}

Previously we noted that ectopic bone formation by ASCs can be induced by the addition of exogenous rhBMP2 to the culture medium or TEC (Mehrkens et al., 2012). In another study, we showed that aggregation stimulates ectopic bone formation by BM-MSCS (Chatterjea et al., 2013). To investigate whether the TEC strategy is sufficient to drive ectopic bone formation, TECs with either BMMSC- or ASC-spheroids were implanted subcutaneously in immunedeficient mice. After 6 weeks the samples were analysed histologically and scored for bone formation. TECs containing BM-MSC spheroids yielded bone in seven of 10 mice. Abundant mineralized matrix with embedded osteocytes was observed. By contrast, no bone and no spheroids were observed in ASC-based TECs (Figure 4). We repeated the experiments and included SVF spheroids and rhBMP2 as variables. This time, three donors of ASCs and SVF (ASCs were derived from the same donors as SVF) and one BM-MSC donor were used. We used the same donor of BM-MSC as before as a constant factor between studies. The six conditions were: TECs with ASCs, TECs with BM-MSC, 

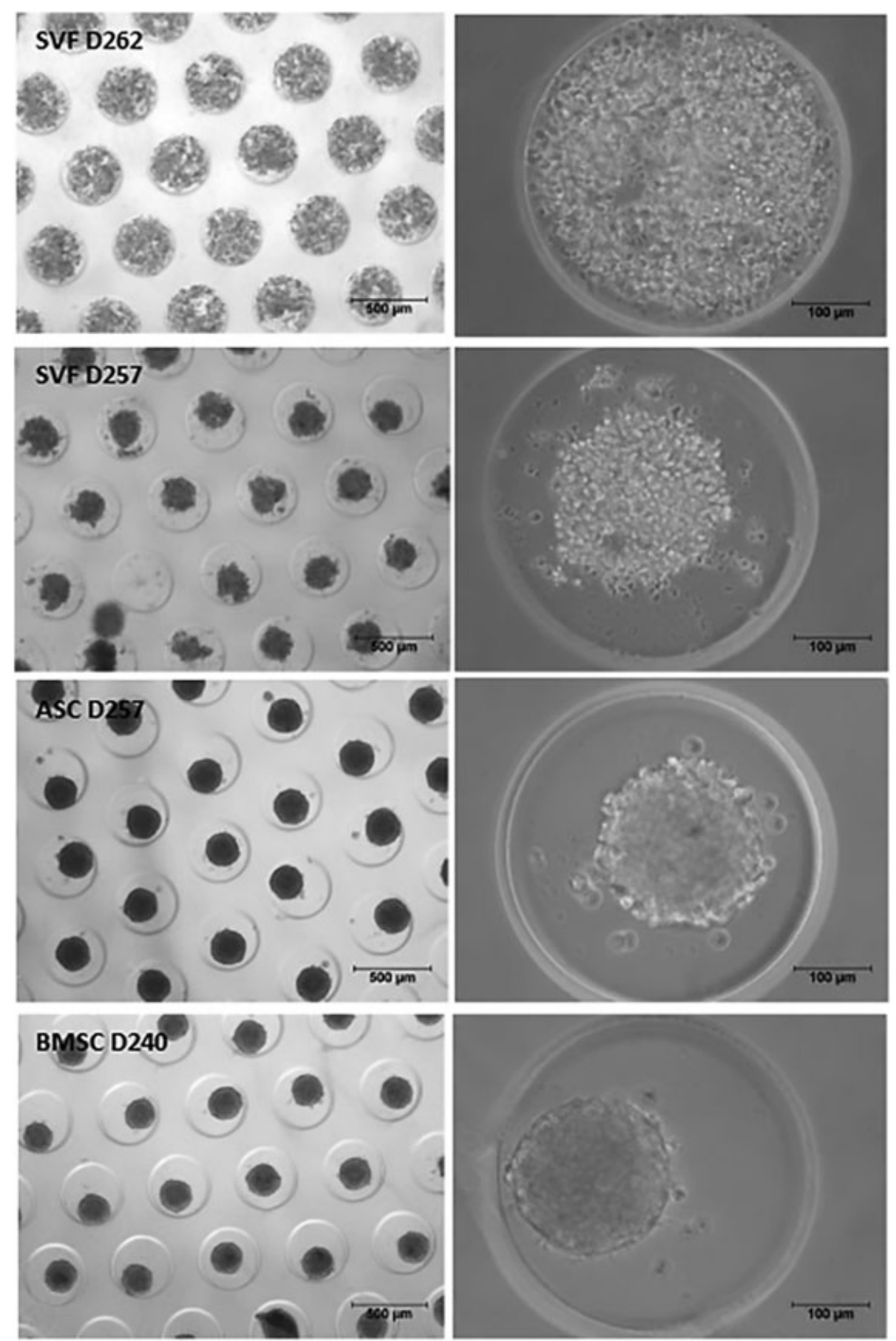

FIGURE 2 Spheroid formation seems to be cell source dependent. Cells were cultured for $24 \mathrm{~h}$ in multiwell agarose chips. In the overview images of the microwells (left column), differences in condensation of the spheroids can clearly be seen. The enlargements show this in great detail (right column) for one microwell. Large differences in condensation were seen in stromal vascular fraction (SVF) cells (compare donor 262 with 257 in the first and second rows), which showed the least condensed spheroids if condensed at all. We observed improved spheroid formation in adiposederived mesenchymal stromal cells (ASCs; third row) and superior condensation in bone marrow mesenchymal stromal cells (BM-MSCs; fourth row). The latter two being representative images of all spheroids. Scale bars indicate either $500 \mu \mathrm{m}$ (left column) or $100 \mu \mathrm{m}$ (right column)

TECs with SVF (with and without BMP2), no cells and no cells with BMP2. The results are summarized in Table 1 . Without cells, no bone was observed (Figure 5A), indicating that neither fibrin gel nor the calcium phosphate ceramics have sufficient osteoinductive features to induce bone tissue formation. By contrast, the addition of rhBMP2 induced bone formation in $2 / 9$ mice (Figure 5B, C). One SVF-TEC showed bone formation (Figure 5D). TECs containing BM-MSC spheroids displayed bone formation in 7/9 mice (Figure $5 \mathrm{H}, \mathrm{I}$ ). Interestingly, this time bone formation was observed in TECs containing ASC aggregates, although only in one of nine mice (Figure $5 \mathrm{G}$ shows an ASC-TEC without bone formation). Similarly, bone formation was observed in SVF-TECs in 1/9 mice, which increased to $4 / 9$ mice when rhBMP2 


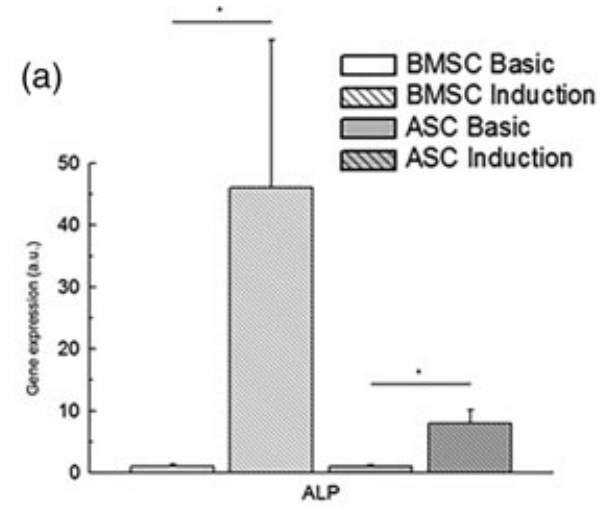

(b)
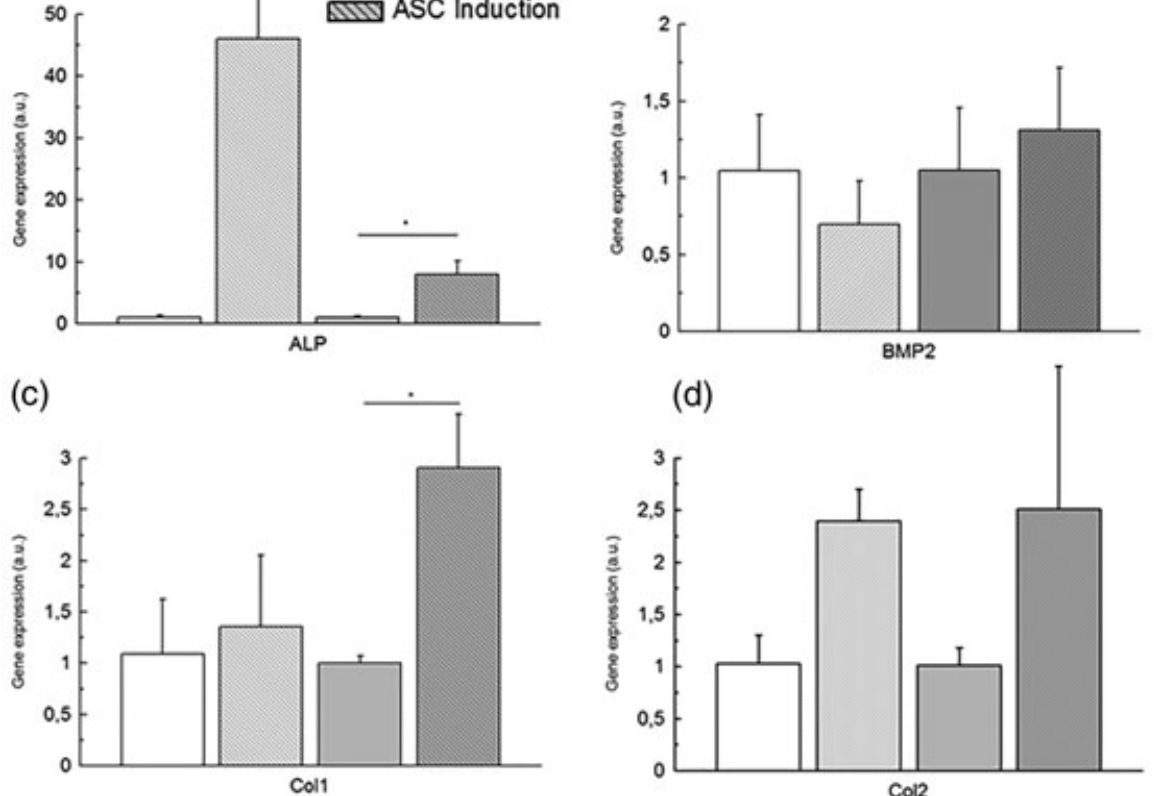

(d)
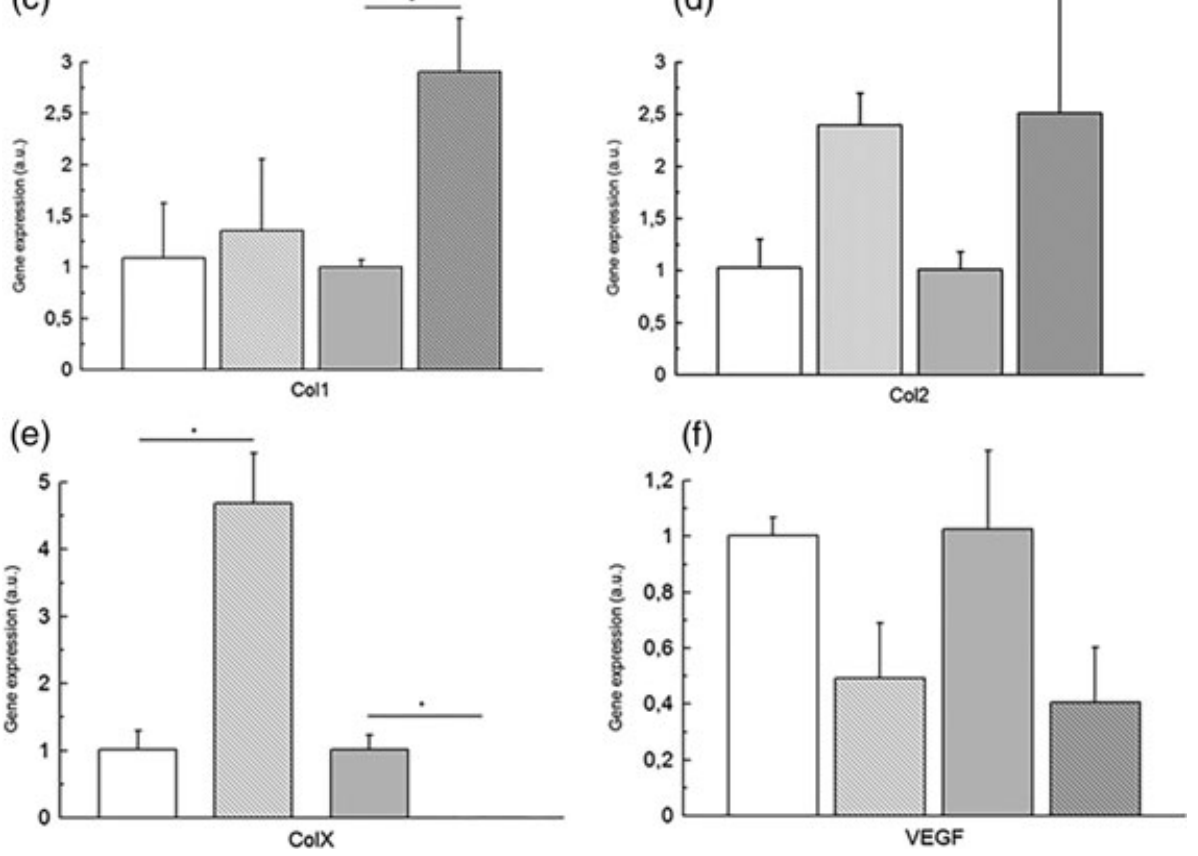

FIGURE 3 Differentiation patterns differ between adipose-derived (ASCs) and bone marrow mesenchymal stromal cells (BM-MSCs) in induction medium. Tissue engineered constructs (TECs) with ASCs and BM-MSCs were cultured for 7 days in either basic or induction medium to simulate implantation. Gene expression was related to the control (basic medium). For osteogenic differentiation, alkaline phosphatase (ALP), BMP2 and collagen type I expression was measured: ALP was significantly upregulated in ASCs and BM-MSCs (a), whereas BMP2 expression (b) was not significantly different between conditions. The collagen type I expression (c) was significantly elevated in induced ASCs but not in BM-MSCs. The chondrogenic differentiation was analysed with collagen type II and collagen type X. Collagen type II was significantly upregulated in induced BMMSCs only (d). The expression of collagen type $X(e)$ was increased upon induction in BM-MSCs, but decreased in ASCs. Vasculogenesis was measured with VEGF expression, but did not differ between conditions ( $f$ )

was included in the TEC (Figure 5E, F). Evaluation of the histological slides further showed that BM-MSC TECS showed the most mature bone, followed by SVF + rhBMP2 and no cells + rhBMP2.

\section{4 | DISCUSSION}

Bone graft substitutes are not yet commonplace in the treatment of large bone defects. Several hurdles still hinder the adoption of this treatment modality. One important factor is the number of autologous stromal cells that can be harvested, because high numbers of cells are generally required. Another factor is the ease of harvest. Readily available cell sources could catalyse their clinical use. The comparison of stromal cells derived from adipose tissue vs. bone marrow is therefore meaningful. Adipose tissue is indeed an easier source for stromal cells than bone marrow. The exact yield per $\mathrm{ml}$ of adipose tissue vs. bone marrow is hard to compare due to different yields of stromal cells in the literature. For instance, the ratio in stromal cell yield of adipose tissue/bone marrow can range from 7-fold to 40-fold (Bieback, Kern, Kocaomer, Ferlik, \& Bugert, 2008; Strem et al., 2005). On average, yields of $1.5 \times 10^{5}$ SVF cells are typically obtained with the manual isolation procedure, of which $10 \%$ are clonogenic ASC (Güven et al., 2011). Despite these differences, adipose tissue is easier to obtain and in larger quantities. Hence, it remains an attractive alternative to bone marrow.

When using SVF cells directly to form spheroids, we noticed that the spheroid formation was very different from donor to donor, unlike ASCs and BM-MSCs. BM-MSCs and ASCs are less heterogeneous than 
(a)

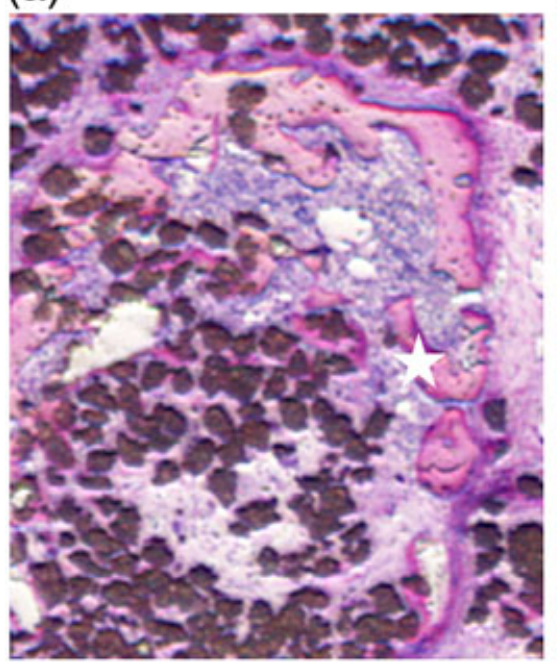

(b)

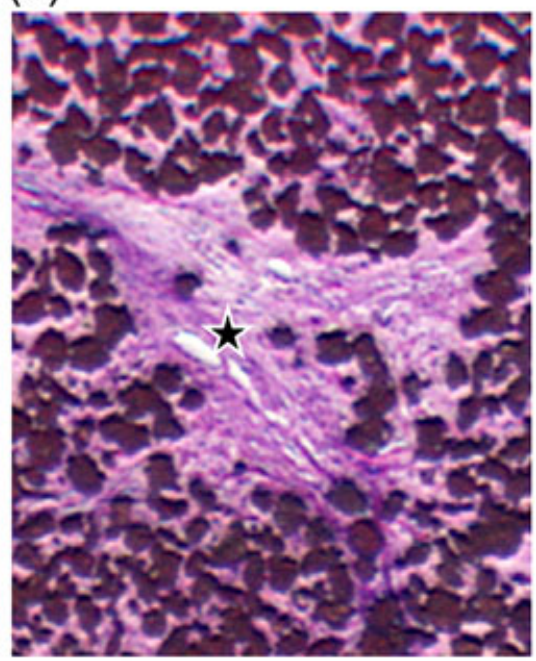

FIGURE 4 Bone marrow mesenchymal stromal cells (BM-MSCs) show bone formation in vivo. To compare the bone-forming capacity of adipose-derived mesenchymal stromal cells (ASCs) and BM-MSCs both were implanted in NMRI-nu mice. BM-MSC-based tissue engineered constructs (TECS) showed mature bone formation (a) indicated with a white asterisk. ASC-based TECs (b) only showed fibrous tissue, indicated with a black asterisk. Scaffolds are black in (a) and (b). In total 7/10 mice with BM-MSC TECs showed bone formation, compared with $0 / 10$ in ASCs. All samples in this study were embedded in methyl methacrylate and stained with methylene blue and basic fuchsin (a)

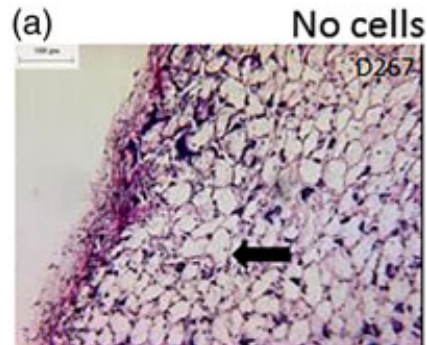

(d)

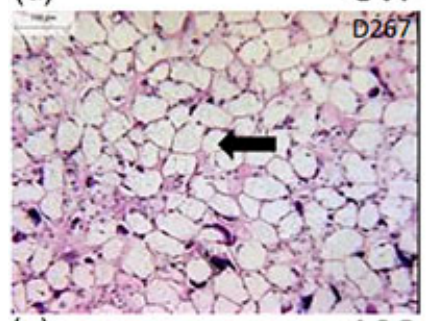

(g)

ASC

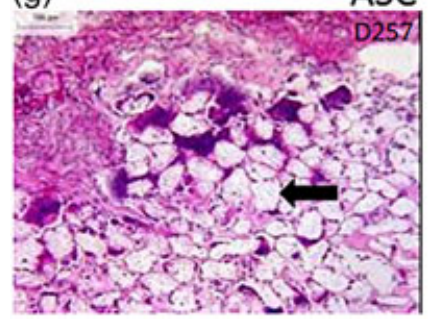

(b) No cells + rhBMP2

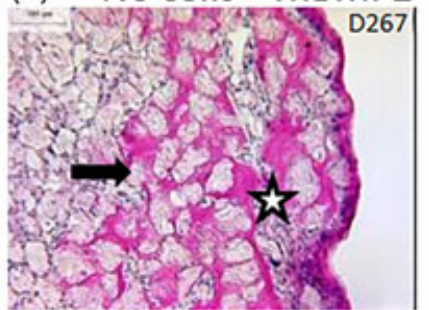

(e) $\quad$ SVF + rhBMP2 (c) No cells + rhBMP2

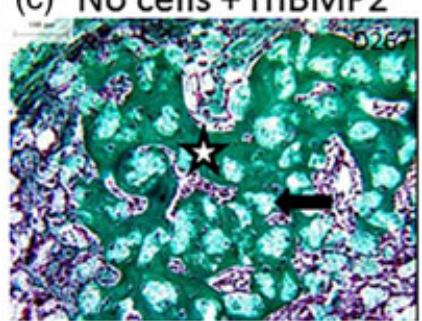

(f)
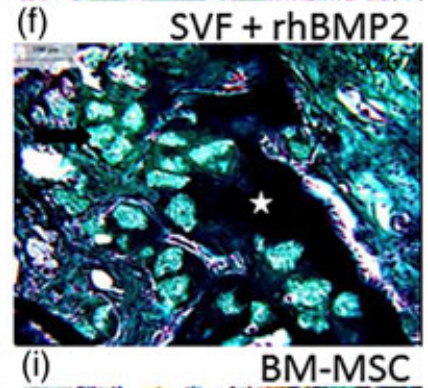
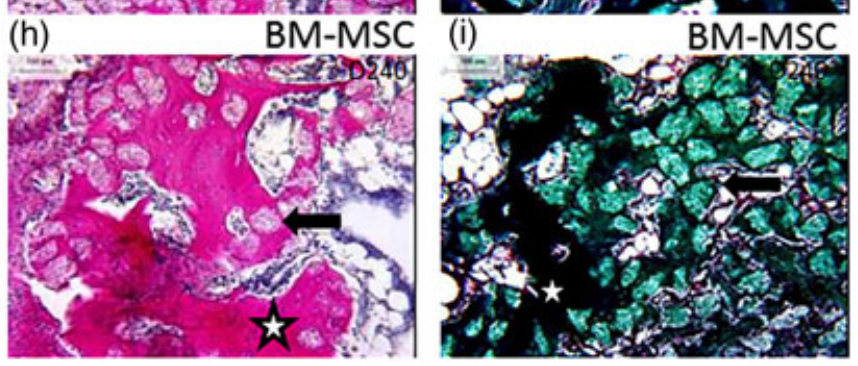

FIGURE 5 Bone marrow mesenchymal stromal cells (BM-MSCs) show more and more mature bone formation. The previous experiment was repeated with the addition of more conditions to see if bone formation could be achieved with adipose-derived mesenchymal stromal cells (ASCs) and stromal vascular fraction (SVF). Six conditions were created: tissue engineered constructs (TECs) with ASCs, TECs with BM-MSC, TECs with SVF (with and without rhBMP2), no cells, no cells with rhBMP2. In TECs without cells we did not observe bone formation (a), only scaffolds (black arrow). When rhBMP2 was added, bone formation (bright pink, asterisk) was seen in 2/9 mice (b). This was confirmed with Masson's trichrome staining (c). SVF showed bone on one occasion, but usually no bone was seen (d). When rhBMP2 was added (e), bone formation was seen in 4/9 mice (bright pink, asterisk) next to ceramic scaffolds (black arrow). Masson's trichrome staining (f) shows mature bone formation (asterisk) next to scaffolds (black arrow). ASCs alone did not show any bone formation (g), only scaffolds (black arrow). BM-MSC-based TECs showed the highest bone incidence (7/9) and the most mature bone (h, i; asterisks)

the source from which they are isolated as adherent cell fraction: red bone marrow and SVF, respectively. The SVF contains cells of the haematopoietic, vascular and mesenchymal lineages. Between studies, the contribution of either of these populations in SVF varies (Bourin et al., 2013). We assume that this variation in cell types might interfere with an efficient aggregation of SVF cells into spheroids. In a previous study we have shown that spheroid formation significantly increases osteogenic differentiation in vitro and bone formation in vivo (Chatterjea 
et al., 2013). Subsequently, we hypothesize that hampered spheroid formation results in less (if any) bone formation that can probably only be rescued by prolonged culturing and/or addition of rhBMP2.

Next to the hampered spheroid formation in vitro we observed less bone formation in vivo in the SVF TECs (with or without the addition of rhBMP2). We can only speculate whether this is due to the lack of spheroid formation or the relatively lower number of MSCs in the SVF TECs, because the cell numbers are based on mononuclear cell count. It is important to note, however. That this was the first time ectopic bone formation by SVF cells was observed without any extensive in vitro priming or addition of rhBMP2 (Mehrkens et al., 2012). Furthermore, we observed more mature bone in TECs with BMMSCs than with SVF + rhBMP2. The use of rhBMP2 in patients is currently restricted to spinal fusion and tibial non-union. Several adverse events have been described following treatment with rhBMP2, such as heterotopic ossification (Woo, 2013) and a higher incidence of cancer (Cooper \& Kou, 2013). Although these reports should not be considered as causative analyses, a cell-based approach seems more favourable, even if the doses used in the present study were much lower as compared with the surgically used, rhBMP2-based products.

We observed the highest bone incidence when using BM-MSCs and the bone formed also showed a higher degree of maturity as compared with ASCs. This poses the question if this might be related to their organ of origin. A common feature of MSC sources is that they are situated in the vicinity of vascular structures (Putnam, 2014). Furthermore, there is evidence suggesting that BM-MSCs are more prone to osteogenic differentiation than ASCs from the same donor (Im, Shin \& Lee, 2005) and are programmed for skeletal development, as they express RUNX3, RUNX2, BGLAP, MMP13 and ITGA10, whereas ASCs do not (Reinisch et al., 2015). This 'innate' tendency for skeletal development of BM-MSCs might explain why they form bone more reproducibly and also more mature bone than ASCs. Moreover, some suggest that ASCs exhibit reduced chondrogenic capacity and proangiogenic activity (Brocher et al., 2013). Our study compared ASCs and BM-MSCs and their capacity for osteogenic differentiation in vitro and bone formation in vivo using spheroids without extensive (chondrogenic or osteogenic) in vitro priming of implanted constructs. We can confirm the lack of proangiogenic activity in vitro, as shown by the absence of VEGF induction. This might be due to the chondrogenic nature of the induction medium used (which is the same as chondrogenic differentiation medium, but without the transforming growth factor- $\beta$ ), which should not stimulate vasculogenesis, as cartilage is avascular. After 1 week of in vitro culture with this induction medium, Col II was significantly upregulated only in BM-MSCs. This is in line with the results of others that also showed that ASCs in micromass culture show reduced chondrogenic differentiation capacity in vitro and could only be induced by the addition of transforming growth factor- $\beta$ and BMP6 (Hennig et al., 2007). As there was no analysis carried out on the origin of the bone, no claims can be made regarding the contribution of host vs. donor cells and the differences between ASCs and BM-MSCs herein.

We conclude that aggregation can improve ectopic bone tissue formation by adipose-derived cells, but is less efficient than rhBMP2. Furthermore, in this system, BM-MSCs showed quantitatively and qualitatively superior ectopic bone formation without additional growth factors. A combination of aggregated ASCs and rhBMP2 should now be tested to investigate a possible additive effect. In addition, a high throughput screening of small molecules to optimize aggregation in ASCs might render rhBMP2 unnecessary.

\section{ACKNOWLEDGEMENTS}

We acknowledge the financial support of Pieken in de Delta OostNederland (PID091014) (EF, JdB and CvB). JdB and CvB acknowledge the financial support of the Dutch province of Limburg. This study was supported by the Swiss National Science Foundation, SNF grant \#310030-138519 (AS and IM).

\section{CONFLICT OF INTEREST}

The authors have declared that there is no conflict of interest.

\section{ORCID}

Eelco M. Fennema $\odot$ http://orcid.org/0000-0002-8086-4516

\section{REFERENCES}

Bao, B. A., Lai, C. P., Naus, C. C., \& Morgan, J. R. (2012). Pannexin1 drives multicellular aggregate compaction via a signaling cascade that remodels the actin cytoskeleton. Journal of Biological Chemistry, 287(11), 8407-8416.

Bieback, K., Kern, S., Kocaomer, A., Ferlik, K., \& Bugert, P. (2008). Comparing mesenchymal stromal cells from different human tissues: bone marrow, adipose tissue and umbilical cord blood. Bio-medical Materials and Engineering, 18(1 Suppl), S71-S76.

Bierwolf, J., Lutgehetmann, M., Feng, K., Erbes, J., Deichmann, S., Toronyi, E., ... Pollok, J. M. (2011). Primary rat hepatocyte culture on 3D nanofibrous polymer scaffolds for toxicology and pharmaceutical research. Biotechnology and Bioengineering, 108(1), 141-150.

Bourin, P., Bunnell, B. A., Casteilla, L., Dominici, M., Katz, A. J., March, K. L., ... Gimble, J. M. (2013). Stromal cells from the adipose tissue-derived stromal vascular fraction and culture expanded adipose tissue-derived stromal/stem cells: a joint statement of the International Federation for Adipose Therapeutics and Science (IFATS) and the International Society for Cellular Therapy (ISCT). Cytotherapy, 15(6), 641-648.

Brocher, J., Janicki, P., Voltz, P., Seebach, E., Neumann, E., Mueller-Ladner, U., \& Richter, W. (2013). Inferior ectopic bone formation of mesenchymal stromal cells from adipose tissue compared to bone marrow: rescue by chondrogenic pre-induction. Stem Cell Research, 11(3), 1393-1406.

Chatterjea, A., Yuan, H., Fennema, E., Burer, R., Chatterjea, S., Garritsen, H., ... de Boer, J. (2013). Engineering new bone via a minimally invasive route using human bone marrow-derived stromal cell aggregates, microceramic particles, and human platelet-rich plasma gel. Tissue Engineering Part A, 19(3-4), 340-349.

Cooper, G. S., \& Kou, T. D. (2013). Risk of cancer after lumbar fusion surgery with recombinant human bone morphogenic protein-2 (rhBMP-2). Spine, 38(21), 1862-1868.

Gamie, Z., Tran, G. T., Vyzas, G., Korres, N., Heliotis, M., Mantalaris, A., \& Tsiridis, E. (2012). Stem cells combined with bone graft substitutes in skeletal tissue engineering. Expert Opinion on Biological Therapy, 12(6), 713-729.

Gimble, J. M., Grayson, W., Guilak, F., Lopez, M. J., \& Vunjak-Novakovic, G. (2011). Adipose tissue as a stem cell source for musculoskeletal regeneration. Frontiers in Bioscience, 3, 69-81.

Gimble, J. M., Katz, A. J., \& Bunnell, B. A. (2007). Adipose-derived stem cells for regenerative medicine. Circulation Research, 100(9), 1249-1260. 
Güven, S., Mehrkens, A., Saxer, F., Schaefer, D. J., Martinetti, R., Martin, I., \& Scherberich, A. (2011). Engineering of large osteogenic grafts with rapid engraftment capacity using mesenchymal and endothelial progenitors from human adipose tissue. Biomaterials, 32(25), 5801-5809.

Hennig, T., Lorenz, H., Thiel, A., Goetzke, K., Dickhut, A., Geiger, F., \& Richter, W. (2007). Reduced chondrogenic potential of adipose tissue derived stromal cells correlates with an altered TGFbeta receptor and BMP profile and is overcome by BMP-6. Journal of Cellular Physiology, 211(3), 682-691.

Im, G. I., Shin, T. W., \& Lee, K. B. (2005). Do adipose tissue-derived mesenchymal stem cells have the same osteogenic and chondrogenic potential as bone marrow-derived cells? Osteoarthritis and Cartilage, 13(10), 845-853.

Mehrkens, A., Saxer, F., Guven, S., Hoffmann, W., Muller, A. M., Jakob, M., ... Scherberich, A. (2012). Intraoperative engineering of osteogenic grafts combining freshly harvested, human adipose-derived cells and physiological doses of bone morphogenetic protein-2. European Cells and Materials, 24, 308-319.

Meijer, G. J., de Bruijn, J. D., Koole, R., \& van Blitterswijk, C. A. (2008). Cell based bone tissue engineering in jaw defects. Biomaterials, 29(21), 3053-3061.

Putnam, A. J. (2014). The instructive role of the vasculature in stem cell niches. Biomaterial Science, 2(11), 1562-1573.

Reinisch, A., Etchart, N., Thomas, D., Hofmann, N. A., Fruehwirth, M., Sinha, S., ... Strunk, D. (2015). Epigenetic and in vivo comparison of diverse MSC sources reveals an endochondral signature for human hematopoietic niche formation. Blood, 125(2), 249-260.

Rivron, N. C., Raiss, C. C., Liu, J., Nandakumar, A., Sticht, C., Gretz, N., ... van Blitterswijk, C. A. (2012). Sonic Hedgehog-activated engineered blood vessels enhance bone tissue formation. Proceedings of the National Academy of Sciences of the United States of America, 109(12), 4413-4418.

Sakaguchi, Y., Sekiya, I., Yagishita, K., \& Muneta, T. (2005). Comparison of human stem cells derived from various mesenchymal tissues: superiority of synovium as a cell source. Arthritis \& Rheumatology, 52(8), 2521-2529.

Scherberich, A., Galli, R., Jaquiery, C., Farhadi, J., \& Martin, I. (2007). Threedimensional perfusion culture of human adipose tissue-derived endothelial and osteoblastic progenitors generates osteogenic constructs with intrinsic vascularization capacity. Stem Cells, 25(7), 1823-1829.

Shen, F. H., Werner, B. C., Liang, H., Shang, H., Yang, N., Li, X., ... Katz, A. J. (2013). Implications of adipose-derived stromal cells in a 3D culture system for osteogenic differentiation: an in vitro and in vivo investigation. Spine Journal, 13(1), 32-43.

Siddappa, R., Licht, R., van Blitterswijk, C., \& de Boer, J. (2007). Donor variation and loss of multipotency during in vitro expansion of human mesenchymal stem cells for bone tissue engineering. Journal of Orthopaedic Research, 25(8), 1029-1041.

Siddappa, R., Martens, A., Doorn, J., Leusink, A., Olivo, C., Licht, R., ... de Boer, J. (2008). cAMP/PKA pathway activation in human mesenchymal stem cells in vitro results in robust bone formation in vivo. Proceedings of the National Academy of Sciences of the United States of America, 105(20), 7281-7286.

Strem, B. M., Hicok, K. C., Zhu, M., Wulur, I., Alfonso, Z., Schreiber, R. E., ... Hedrick, M. H. (2005). Multipotential differentiation of adipose tissuederived stem cells. Keio Journal of Medicine, 54(3), 132-141.

Woo, E. J. (2013). Adverse events after recombinant human BMP2 in nonspinal orthopaedic procedures. Clinical Orthopaedics and Related Research, 471(5), 1707-1711.

Zuk, P. A., Zhu, M., Ashjian, P., De Ugarte, D. A., Huang, J. I., Mizuno, H., ... Hedrick, M. H. (2002). Human adipose tissue is a source of multipotent stem cells. Molecular Biology of the Cell, 13(12), 4279-4295.

Zvaifler, N. J., Marinova-Mutafchieva, L., Adams, G., Edwards, C. J., Moss, J., Burger, J. A., \& Maini, R. N. (2000). Mesenchymal precursor cells in the blood of normal individuals. Arthritis Research, 2(6), 477-488.

How to cite this article: Fennema EM, Tchang LAH, Yuan $\mathrm{H}$, et al. Ectopic bone formation by aggregated mesenchymal stem cells from bone marrow and adipose tissue: A comparative study. J Tissue Eng Regen Med. 2018;12:e150-e158. https:// doi.org/10.1002/term.2453 